P0103

\title{
CHARACTERIZATION OF THE INTENSITY DISTRIBUTION IN RETROREFLECTIVE ADHESIVES WITH NEAR FIELD GONIOPHOTOMETRY
}

\section{Oswaldo Sanchez Junior et al.}

DOI 10.25039/x46.2019.PO103

from

CIE x046:2019

Proceedings

of the

29th CIE SESSION

Washington D.C., USA, June 14 - 22, 2019

(DOI 10.25039/x46.2019)

The paper has been presented at the 29th CIE Session, Washington D.C., USA, June 14-22, 2019. It has not been peer-reviewed by CIE.

\section{(C) CIE 2019}

All rights reserved. Unless otherwise specified, no part of this publication may be reproduced or utilized in any form or by any means, electronic or mechanical, including photocopying and microfilm, without permission in writing from CIE Central Bureau at the address below. Any mention of organizations or products does not imply endorsement by the CIE.

This paper is made available open access for individual use. However, in all other cases all rights are reserved unless explicit permission is sought from and given by the CIE.

CIE Central Bureau

Babenbergerstrasse 9

A-1010 Vienna

Austria

Tel.: +4317143187

e-mail: ciecb@cie.co.at

www.cie.co.at 


\title{
CHARACTERIZATION OF THE INTENSITY DISTRIBUTION IN RETROREFLECTIVE ADHESIVES WITH NEAR FIELD GONIOPHOTOMETRY
}

\author{
Sanchez Junior, O. ${ }^{1}$, Silva, E.S. ${ }^{2}$, Vitro, J.G. ${ }^{1}$, Barros, K.N. ${ }^{1,3}$, Moreira, R.M.C. ${ }^{1,4}$ \\ 1 Institute for Technological Research - IPT, São Paulo, BRAZIL, ${ }^{2}$ University of São Paulo - USP, \\ São Paulo, BRAZIL, ${ }^{3}$ Federal University of ABC - UFABC, Santo André, BRAZIL, ${ }^{4}$ Foundation \\ Armando Alvares Penteado - FAAP
}

DOI 10.25039/x46.2019.PO103

\begin{abstract}
This paper aims to present the proposal of a new method for the determination of retroreflective coefficients of microprism films by goniophotometry. For this purpose, a specimen was prepared with the application of a microprismatic retroreflective film on a rigid plate and its positioning was carried out in the geometric reference center for measurements of the goniophotometer by means of a suitable support. A small projector with light beam directed to the retroreflective film was attached to the goniophotometer sensor. At the end the light scatter plot and the luminance of the film surface were obtained. With the values obtained, the retroreflecting coefficients were calculated and the scatter plot of the retroreflecting coefficients was obtained. The results were compared with the conventional method presenting convergence with low deviation. In this way it was demonstrated that the process, with minor corrections, can be used as an alternative to the traditional method.
\end{abstract}

Keywords: Goniophotometry, retroreflection coefficient, retroreflective band, micro prismatic.

\section{Introduction}

\subsection{The definition of retroreflection}

Retroreflection is the distinct phenomena of regular or diffuse reflection, in which the material preferably reflects the light rays in parallel and opposite directions to the incidents (Figure 1); this property is intrinsic to the material, so even the angles of the incident rays being varied, it is maintained. (CIE 054.2 2001).

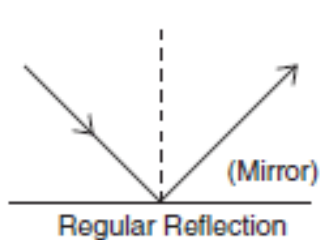

Regular Reflection

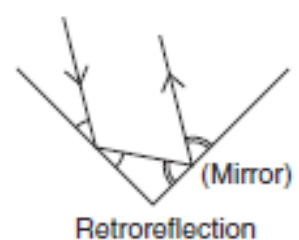

Retroreflection

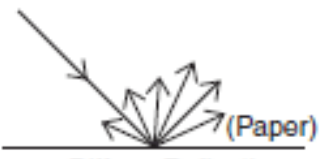

Diffuse Reflection

Figure 1 - Characteristic graphic of the retroreflection phenomenon

Retroreflection uses three physical principles: specular reflection (such as a mirror or highly polished surface), refraction (the change of direction of light as it passes from one medium to another, eg air to glass), and total internal reflection (where light strikes the surface of a transparent material at certain angles jumps from the surface instead of passing) (J. Lloyd 2008) Retroreflection, as defined by CIE $54.2(2001)$, is the "luminous intensity coefficient" expressed in the unit representing the candela value in the observer direction per lux produced perpendicular to the beam incident (cd.1x-1m-2). (J. J. B. MOERMAN,1982).

\subsection{The micro prismatic structure}

A micro prismatic structure in a retroreflective is responsible for the phenomenon of retroreflection. If you take a solid glass cube and separate a corner with a cut that passes along the diagonals of three adjacent faces you get the basic cube-corner unit, the microprism, which is a triangular pyramidshaped prism. (Figure 2). 

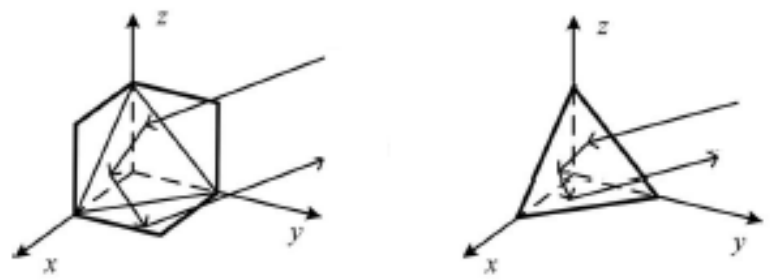

Figure 2 - Representation of the micro-prismatic structure of the retroreflective material and the process of reflections inside it (YIMIN LOU., 2010).

When the pyramid, configured with the triangular base, is exposed to a light beam, which passes through the base with little loss of energy, before being refracted by the base parallel to the incoming beam, it is internally reflected on each of the faces internal controls. (J. LLOYD 2008). The retroreflective strip is a film that can be constituted by glass beads or prisms (Figure 3). The retroreflective strips with microprisms are results of the mosaic of pyramidal prisms, to serve as mirrors in the direction of light and refraction to its source.

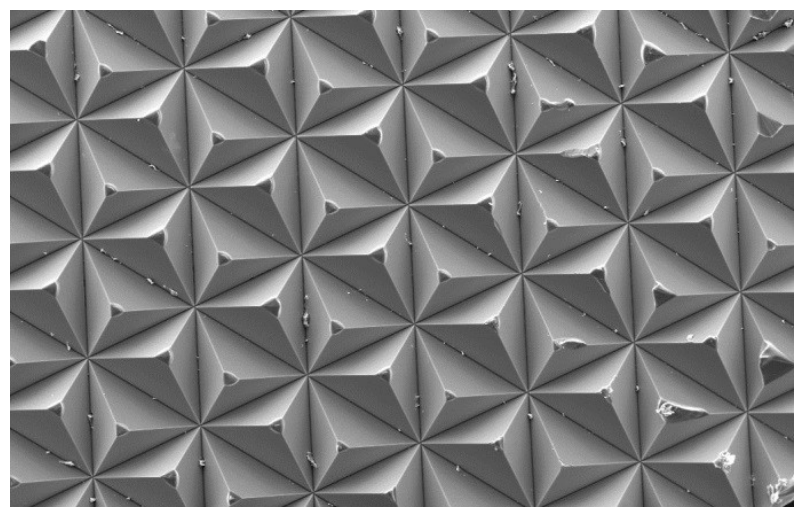

Figure 3 - Photograph of the micro prismatic structure of the retroreflective tape.

\subsection{Goniophotometry}

The goniophotometers are equipment used for the measurement of the luminous distribution of luminous bodies. The name derives from goniometers whose purpose is to measure angles. With the addition of the photometer, the equipment gains the ability to measure optical characteristics, such as total luminous flux (given in lumens), graphs of intensity distribution (given in candelas), angle of luminous beam.

With this equipment we can extract characteristics of light scattering with depth, as a function of the angular space of measurement of $0.1^{\circ}$. In the photometries it is possible to visualize the angular luminous distribution and to determine classifications of products determining the place of use.

There are several types of goniophotometer constructions. Among goniophotometers type $C$ are ideal for measurements where the object to be measured is stationary. 


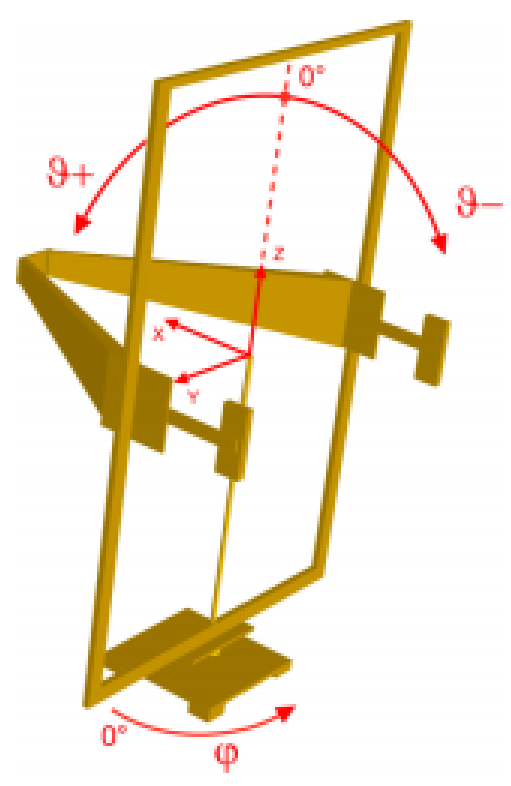

Figure 4-Graphic representation of the type $C$ giofotometers, in the center center is positioned luminous body to be measured, and on the sides are represented the axis of the sensor displacement. The $\varphi$ and the y represent the horizontal and vertical movement respectively. Guide RiG0801 Goniophotometer, Technoteam 2016.

\section{Method}

The method typically used to determine retroreflection coefficients is based on ASTM E808-01 (2016), E809-08 (2013) and E810-03 (2013). In the method the sample is placed in a goniometer at 15 meters from the light source and receiver photometer. The input angles of the light beam are varied in the goniometer. The sample area, the amount of light that falls on the sample (illuminance in lux) and the intensity of the beam that returns to the photometer (intensity in $\mathrm{cd}$ ) are measured and used to calculate the retroreflection coefficient (Figure 5).

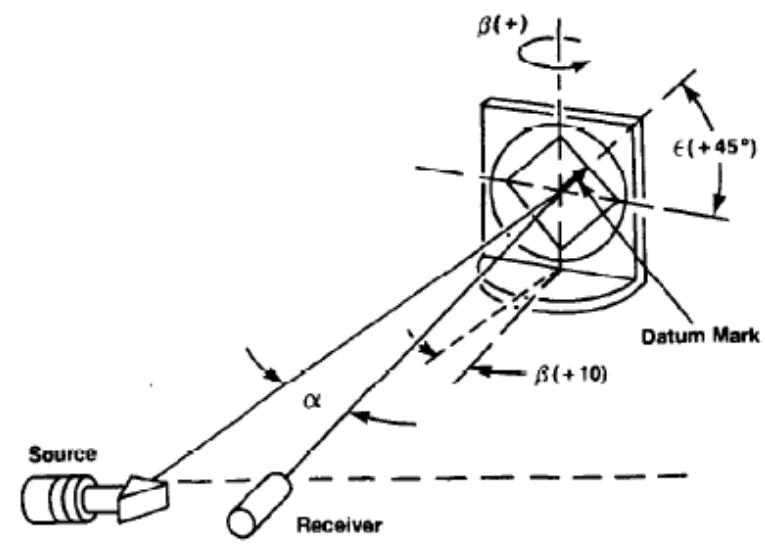

Figure 5 - Experimental arrangement for determining coefficients of retroreflection by ASTM-E810-03 (2013).

In the method proposed by the study, is used an automatic goniofotometer. The sample is placed in the geometric center of rotation of the goniofotometer. For the validation of the new method were adopted the matching of ASTM criteria. In this way a small projector (light source) was placed next to the photometer (observer). A test piece measuring $4.4 \times 4.4 \mathrm{~cm}$ was made and placed in the central region of the goniofotometer, at a distance of $165 \mathrm{~cm}$ from the light source and the photometer. The 
sample size and its distance from the sensor and source were calculated to ensure dimensional proportionality over the conventional method (Figure 6).

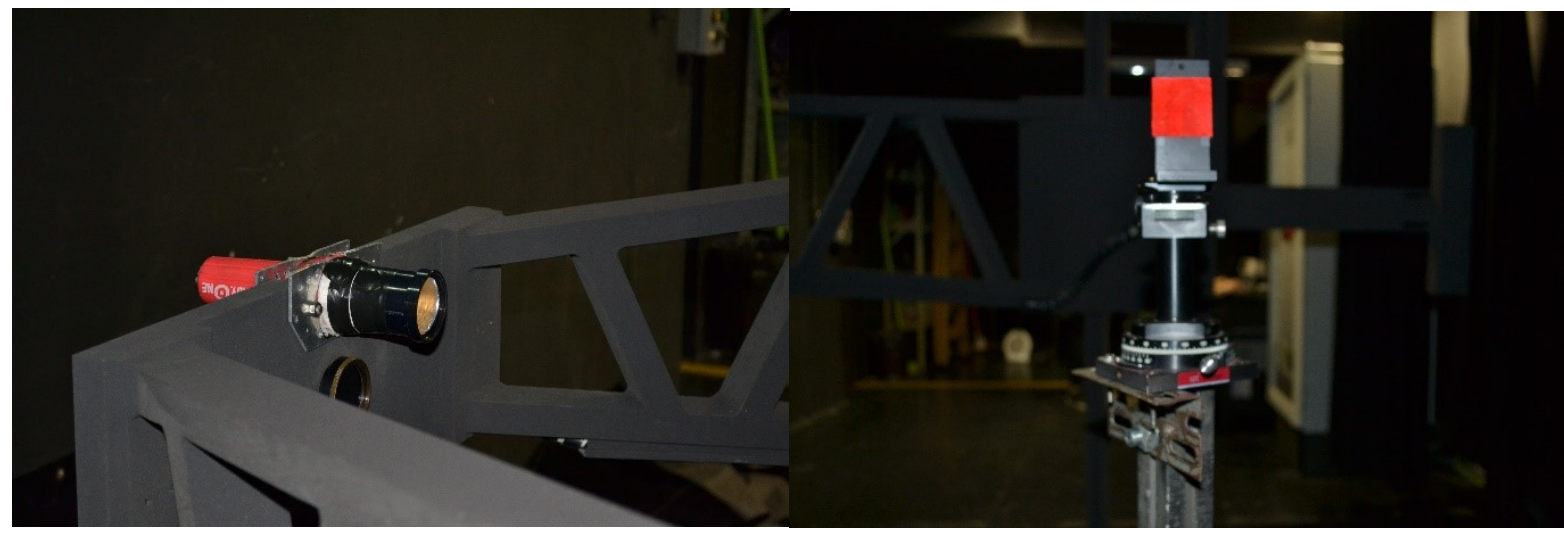

Figure 6 - Flashlight and photometer in the goniophotometer (left), positioner of the sample retroreflective (right).

The method establishes that the gonifotometer must have a minimum resolution of 1 degree, stable and insensitive photometer to light polarization, measurement filters with linearity of the photometric scale and dark room with backlight below $5 \%$ of the light incident on the sample.

Prior to performing the test, the stability of the projector light was checked. The value obtained was below $0.5 \%$ within 30 minutes within the test duration time. (Figure 7 ).

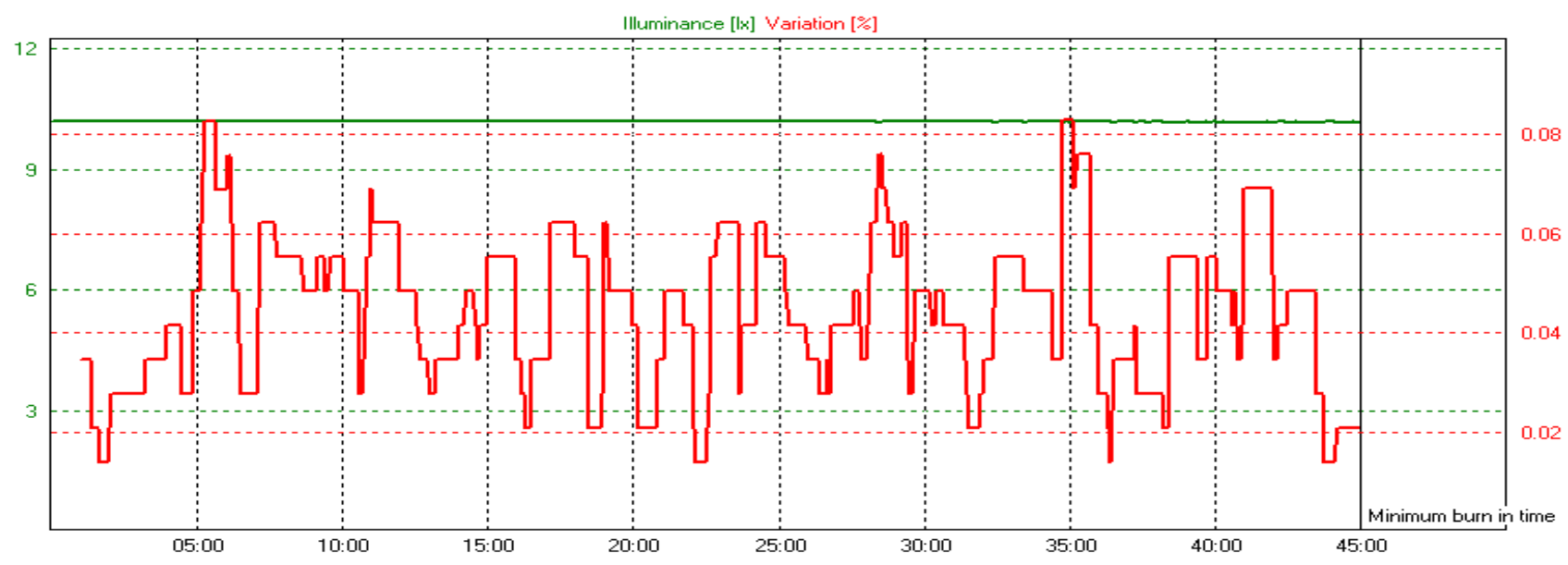

Figure 7 - Measuring the stability of the light emission of the projector. In red the variation of the stability in percentage. In green the illuminance of the light source.

To reduce the measurement time, after checking the retroreflective profile, a $60^{\circ}$ measurement field was adopted on the sides of $\varphi$ and $\gamma$, with respect to the normal axis at the sample surface. Finally, the angular step of $0.5^{\circ}$ measurement was adopted for both $\varphi$ and $\gamma$ axes.

The components of the Ra parameter were obtained as follows:

- luminous intensity of the reflecting surface in the direction of observation: obtained directly by the goniofotometer, weighted by the total reflected flux (measured with fixed source in relation to the sample);

- illuminance in the sample plane: measured with a photometer in the sample plane;

- sample area: measured with caliper. 


\section{Results}

The results of the tests performed on the test body are presented in a graph of light intensity distribution, which can be interpreted as a distribution of retroreflections because the only variable parameter is the angular position of both the projector and the sensor, which are solidary (Figure 8). Since the return-reflective materials exhibit predominantly specular reflection, the distance between the photometer and the projector, although fixed, influences the deviation of the beam. In this way, the placement of the projector above the sensor causes a deviation of $2^{\circ}$ in the $\mathrm{Y}$ axis that can be diagnosed and compensated in the calculations, for comparison purposes with normative requirements, depending on the use made of the retroreflective material.

The following polar graph shows the light distribution of the return beam with the maximum point on the $\varphi$ axis, C 90-0 - C270-0.

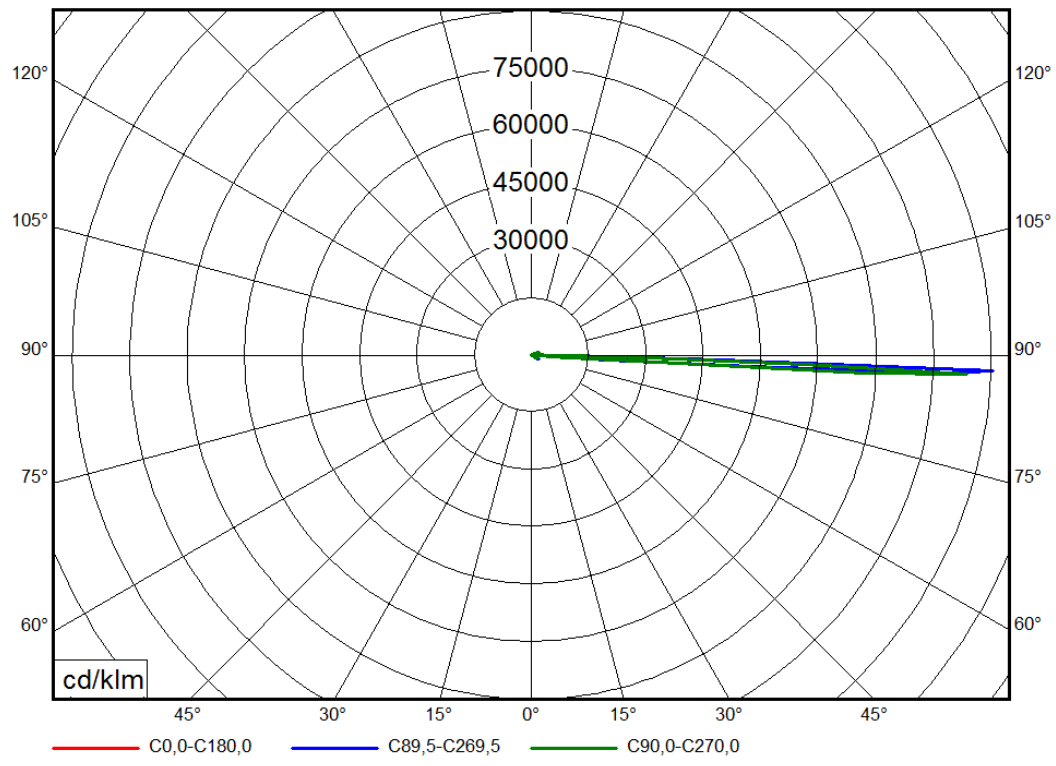

Figure 8 - Distribution chart of retroreflections from the micro prismatic test sample.

For the maximum Intensity values, a Retroreflectance Coefficient of $279.8 \mathrm{~cd} / \mathrm{Ix}{ }^{-1} \cdot \mathrm{m}^{-2}$ was obtained. By the conventional method, this value was $222.4 \mathrm{~cd} / \mathrm{Ix}^{-1} \cdot \mathrm{m}^{-2}$, with the angular corrections. Therefore, a divergence of $20 \%$ was found.

\section{Discussion}

The Technical Report CIE 054.2-2001, "Retroreflection: Definition \& Measurement", deals with laboratory calibration and measurement techniques, together with basic instrument requirements and traceability to national metrology laboratories (chapter 6). However, since its publication, white light LEDs have emerged and the possibility of automating photometric processes with cheaper goniophotometers and the popularization of near field goniophotometry. The standards ASTM E80908-2013 and ASTM E808-01-2016 have advanced when incorporating methodological aspects of proper practice of using goniometers. The fact remains that the use of goniophotometers for retroreflection measurements is limited because the sensors can interfere significantly in the illumination of the sample or vice versa.

In the proposed method, the adaptation of a fixed source of white light LED, with characteristics similar to those of CIE Illuminant A, was performed with very small dimensions, in order to minimize the source-sensor distance effect in the process of raising the curve of distribution of retroreflective light. The experimental arrangement was developed to allow rapid and accurate intervention measures. The validation of the method was carried out with a study of the surface morphology of the samples and an estimate of the distribution profile of the expected retroreflective light, from a normalized and fixed position for the light source in relation to the illuminated surface (geometric optical simulation). Then, this expected profile was compared to the distribution profile obtained by means of the near field 
goniofotometry with the mobile source and solidary to the sensor. Conventional measurements were also performed for the same sample (standardized method) to support the final conclusions.

\section{Conclusion}

Adaptation of a fixed source of white light LED, close to CIE Illuminant $A$, with very small dimensions was carried out, in order to minimize the effect of source-sense distance in the process of lifting the distribution curve of the retroreflective light. The obtained data were compared with an estimate made from the analysis of the surface morphology of the sample and also with the data obtained in the accomplishment of the measurements by the conventional normalized method.

The distribution curves obtained by goniophotometry correspond closely to the expected distribution curves, both for those estimated by the study of the surface morphology and for those obtained by measurements by the conventional standard method. The values of retroreflection coefficients (Ra) obtained diverged on the order of $20 \%$ on average. Although the values were above acceptable, the method demonstrated its pertinence to identify the main directions for the specular reflection of the material and, with this. An analysis of the measurement errors involved, the use of sensors with adequate dynamic range and use of a projector with greater intensity and beam collimation (to give more sensitivity) could reduce this divergence to more acceptable values. It was also observed that the influence of external factors such as the spurious ambient light and the vibration of the LED source support used in the near field goniophotometry can cause significant effects to the result. This leads to the need to improve the experimental arrangement in these aspects.

In general, it has been concluded that the proposed method, after a few modifications, can be a great option for measurements used in fast, cheap and precise processes for the certification of retroreflective adhesive films.

\section{AcknowLedgments}

This work was prepared in collaboration of Electrical and Optical Equipment Laboratory (LEO) of the Institute for Technological Research Sao Paulo (IPT-SP).

\section{References}

CIE 54.2 2001 Retroreflection: Definition and measurement (Paris: Commission Internationale de L'éclairag) p 1-60

MOERMAN J. J. B., CIE Activities in the Measurement of Retroreflection *, KEMA Photometric Laboratory ,COLOR research and application ,p $231-234$.

ASTM E808-01 2016 Standard practice for describing retroreflection,(West Conshohocken: American Society for Testing and Materials) p 1-10.

ASTM E809-08 2013 Standard Practice for Measuring Photometric Characteristics of Retroreflectors(West Conshohocken: American Society for Testing and Materials) p 1-11.

ASTM E810-03 2013 Standard test method for coefficient of retroreflection of retroreflective sheeting utilizing the coplanar geometry(West Conshohocken: American Society for Testing and Materials) p 1-8.

LLOYD J. , A brief history of retroreflective sign face sheet materials, Understanding retrorreflectivity, p $1-4$. 